\title{
Effect of Salt Leaching on PCL and PLGA(50/50) Resorbable Scaffolds
}

\author{
Samuel Hilsdorf Barbanti ${ }^{\mathrm{a}, \mathrm{b}}$, Cecília Amélia Carvalho Zavaglia ${ }^{\mathrm{b}}$ Eliana Aparecida de Rezende Duek ${ }^{\mathrm{a}}$. \\ ${ }^{a}$ Laboratory of Biomaterials, Center of Medical and Biological Sciences, \\ Pontificie Catholic University of São Paulo - PUCSP, \\ Praça Dr. José Ermírio de Moraes, 290, 18030-230 Sorocaba - SP, Brazil \\ ${ }^{\mathrm{b}}$ Department of Materials Engineering, Faculty of Mechanical Engineering, \\ State University of Campinas - UNICAMP, Rua Mendeleiev, s/n, Campinas - SP, Brazil
}

Received: August 18, 2007; Revised: January 23, 2008

\begin{abstract}
The use of porous bioresorbable scaffolds in the field of tissue engineering represents an alternative for the treatment of lesions and losses of biological tissues. This work evaluates the leaching salt effect of two different processes and polymers. Dense and porous scaffolds were prepared with poly(epson-caprolactone) (PCL) and poly(D,L-lactic acid-co-glycolic acid) (50/50) (PLGA50) by casting and melting compression process. Sodium citrate with particles sizes of $180-250 \mu \mathrm{m}$ of diameter was used as porogen. The dense and porous samples were immersed in distilled water for 30 hours and evaluated for $\mathrm{pH}$ and mass variations, by scanning electronic microscopy (SEM), differential scanning calorimetric (DSC) and thermogravimetric analysis (TGA). The results of the analyses showed that the inclusion of the salt and leaching process did not affect the properties of the scaffold, indicating that the method is useful to make porous scaffolds to be potentially used in tissue engineering.
\end{abstract}

Keywords: bioresorbable polymers, poly(epson-caprolactone), poly(D,L-lactic acid-co-glycolic acid), leaching salt

\section{Introduction}

In the field of tissue engineering strategies, the use of biomaterials as cell support is fundamental to the reconstruction of organs and tissues. Many materials can be used as scaffold; however, temporary scaffolds are of great interest because the presence of the support is required during tissue repair, promoting guided tissue growth.

The most widely used bioresorbable materials are aliphatic polyesters such as poly(glycolic acid) (PGA), poly(lactic acid) (PLA), poly(epson-caprolactone) (PCL) and their copolymers. Several bioresorbable medical products are available today, particularly surgical sutures ${ }^{1}$, drug delivery systems ${ }^{2}$, stents ${ }^{3}$ and orthopaedic devices ${ }^{4}$. These polymers are used on a daily basis in surgical centers in the world ${ }^{5}$.

The bioresorbable polyesters undergo enzymatic and hydrolytic degradation. The hydrolysis of the ester bonds into tissue compatible metabolites are used in the carbohydrate metabolism and the products are excreted as water and carbon dioxide ${ }^{6}$. Several factors determine the degradation rate of those polymers, including the site of the implant, the chemistry and stereoisomeric composition of the material, crystallinity, size and morphology of the scaffold, external $\mathrm{pH}$ medium and other parameters ${ }^{7}$. Thus, the in vitro and in vivo degradation studies have been proposed to establish relationships among those factors ${ }^{8,9}$.

Within the many types of bioresorbable material applications, porous morphology is the preferred ones. The presence of pores allows cell penetration and tissue ingrowths. Additionally, the interconnections of pores facilitate nutrient and waste exchange. These characteristics are often dependent on the method of scaffold fabrication. Several techniques have been developed to create bioresorbable porous scaffolds. These processes include solvent casting/ particulate leaching, fiber bonding, gas foaming, phase inversion, solvent removal by freeze-drying, plasticizer addition, etc. ${ }^{10}$. The morphologies and properties of the resulting scaffolds largely depend on the fabrication process.
The technique of salt addition and subsequent leaching has been shown to be useful to prepare porous scaffolds for cell culture ${ }^{11}$. The porosity of the material is created when the composite (polymeric mass and salt) are immersed into distilled water, where salt particles (porogen) are removed by leaching. The leaching process is completed in approximately 24 hours. However, the scaffolds can undergo degradation through hydrolysis as soon as the material is exposed to water. Hence, the objective of this work was to evaluate the influence of the leaching process in the properties of porous resorbable scaffolds prepared by casting and melting compression technique.

\section{Material and Methods}

\subsection{Scaffold fabrication}

Scaffolds were prepared using poly(epson-caprolactone) (PCL), molecular weight (MW) 100,000 g. mol ${ }^{-1}$, supplied by Sigma Co., (St. Louis, MO, USA), and poly(D,L-lactic-co-glycolic acid) (50/50) (PLGA50), MW 65,000 g. $\mathrm{mol}^{-1}$, supplied by Purac (Groningen, The Netherlands). Dense and porous scaffolds were prepared by casting and melting compression process.

\subsubsection{Casting}

The casting process was used to prepare membranes. The PCL and PLGA50 were dissolved in chloroform (Merck KgaA, Darmstadt, Germany), at a concentration of $10 \% \mathrm{w} / \mathrm{v}$, at room temperature. Dense membranes were cast on glass plates and dried for approximately 24 hours in a closed chamber with a constant flow of dry filtered air. Porous membranes were prepared as described above, using a polymer chloroform solution containing $50 \%(\mathrm{w} / \mathrm{v})$ citrate sodium (Fluka Chemicals, Buchs, Switzerland) with particles diameter sizes of 180-250 $\mu \mathrm{m}$. After casting, the samples were cut in $3 \times 3 \mathrm{~cm}$. 


\subsubsection{Melt compression processing}

Dense scaffolds were prepared by compression into a mold (3 x 100 mm) using Mini Max Molder (LMM-2017, Austin, TX, USA) at $160{ }^{\circ} \mathrm{C}$. The mold was cooled at room temperature. Porous scaffolds were prepared with the addition of citrate sodium (Fluka Chemicals) sieved in particles of $180-250 \mu \mathrm{m}$ in diameter and a 2 salt / 1 polymer weight ratio. The salt was added during the polymer melting compression and stirred to obtain a paste-like polymerparticulate mixture. The pins obtained were cut in rod samples of $3 \mathrm{~mm}$ in diameter and $6 \mathrm{~mm}$ in length.

\subsection{Salt leaching}

After solvent evaporation or cooling process, all samples (dense and porous) were immersed in $40 \mathrm{~mL}$ of distilled water for 30 hours. Samples were removed after 1, 6, 20, 24 and 30 hours, washed with ethanol and vacuum dried.

\subsection{Materials characterization}

\subsubsection{Normalized weight and $\mathrm{pH}$ variation}

Immediately before the removal of the samples, the $\mathrm{pH}$ was measured with a Micronal B474. The normalized weight of the samples was calculated by the relation of the dry samples average weight and the average of the initial weight. The analyses were done in triplicate.

\subsubsection{Scanning electron microscopy (SEM)}

A JXA 840 scanning electron microscope (Jeol, Peabody, USA), at a tension of $10 \mathrm{kV}$, was used to observe fractured surfaces. The samples were fractured in liquid nitrogen and coated with gold with a sputter coater SCD 050 Cool Sputter System (Bal-Tec, Balzers, Switzerland). Micrograph analysis was carried out with the freeware software ImageTool ${ }^{\circledR}$ supplied at the site of the Texas University (USA).

\subsubsection{Differential scanning calorimetry (DSC)}

The DSC analysis was carried out in a STA 409C of Netzsch (Gerätebau GmbH Thermal, Selb, Germany) at a temperature variation from 25 to $200{ }^{\circ} \mathrm{C}$ at a rate of $10{ }^{\circ} \mathrm{C} / \mathrm{min}$; each sample was re-heated. The changes in the glass transition temperature $(\mathrm{Tg})$, crystallization temperature (Tc) and melting temperature (Tm) were evaluated. The degree of crystallinity of PCL samples was calculated from the enthalpy change using the equation described in Barbanti

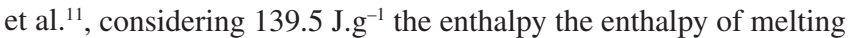
of $100 \%$ crystalline polymer ${ }^{12}$.

\subsubsection{Thermogravimetric analysis (TGA)}

The TGA analysis was carried out in a STA 409C of Netzsch (Gerätebau GmbH Thermal, Selb, Germany). The samples were heated from the room temperature up to $400{ }^{\circ} \mathrm{C}$ at a heating rate of $10^{\circ} \mathrm{C} / \mathrm{min}$ under helium atmosphere.

\section{Results and Discussion}

The normalized mass and $\mathrm{pH}$ variation of PCL and PLGA50 samples are shown in Figure 1. During the salt leaching process, $\mathrm{pH}$ analysis indicated that only samples prepared with sodium citrate had shown variations in $\mathrm{pH}$ which is related to the basic characteristics of the salt. The difference in the declining tendency of samples during the leaching process can be attributed to the sample geometry: the larger the area of contact with the water, the faster the dissociation process is. After 30 hours of immersion in water, the samples presented values similar to the water $\mathrm{pH}$, suggesting that all the salt was removed from the material. Figure 1 also shows that during the leaching process there are no variations of the normalized mass of the samples. Our results suggest that in this case, the degradation was not enough to modify the mass of the samples.

The time of salt leaching varies according to the geometry of samples. The literature does not always specify the immersion time; therefore, the results published may vary from hours ${ }^{9,13}$ to days ${ }^{14,15}$. Given that it is a low cost simple technique, $\mathrm{pH}$ could be used as an indirect measurement of the salt leachate. In our experiment, the equivalence between the $\mathrm{pH}$ of the solution containing the sample and the $\mathrm{pH}$ of the distilled water suggests there are no more particles of salt to be removed.

Immersed in distilled water during the salt removal, the supports can suffer degradation through hydrolysis as soon as the material is exposed to water. The presence of acid terminals, as the result of degradation of the products, reduces the $\mathrm{pH}$ of the medium ${ }^{16}$. It has been demonstrated by fluorescence technique, that PLGA scaffolds presented a significant $\mathrm{pH}$ decrease on the material surface in flat muscles culture, reducing cellular viability after 7 days of culture ${ }^{17}$. Alkaline salts has been utilized as an alternative to the traditionally $\mathrm{NaCl}$ used as porogen. The citrate salt used in this work has higher solubility and allows increase of $\mathrm{pH}$ values; however, at $230{ }^{\circ} \mathrm{C}$ it
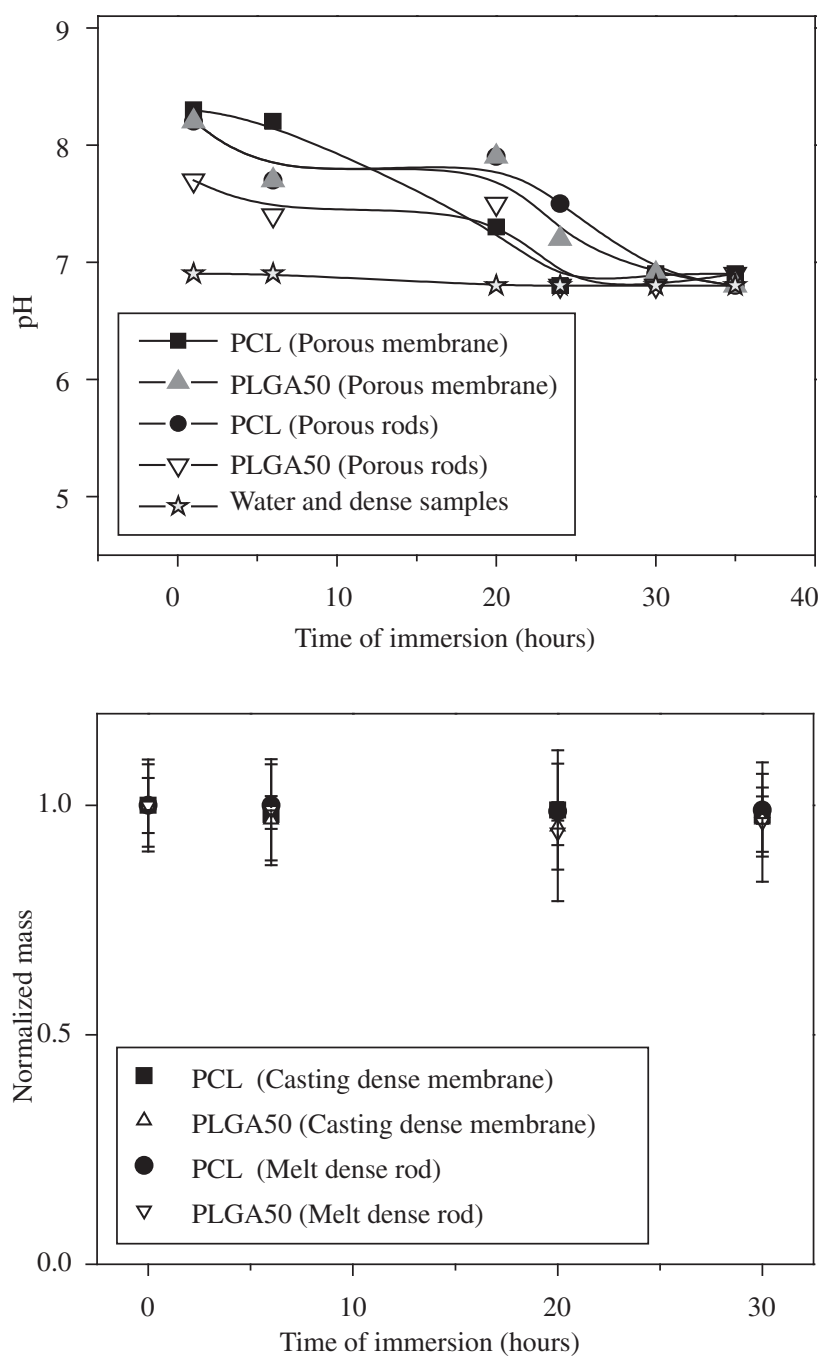

Figure 1. Normalized mass and $\mathrm{pH}$ variation of PCL and PLGA50 samples in distilled water. 
suffers thermal decomposition which represents a limitation for processing at high temperatures.

In an innovative study, Agrawal and Athanasiou ${ }^{18}$ evaluated the in vitro degradation of PLGA50 samples containing basic salts $\left(\mathrm{CaCO}_{3}, \mathrm{NaHCO}_{3}\right)$ in the polymeric matrix. After 20 days, they observed an inversion of $\mathrm{pH}$ due the degradation of the acid products. In the biological environment, the insertion of salts normally alters the cell electrolytic balance. Additionally, the alkaline medium provokes intense degradation of the bioresorbable scaffolds ${ }^{19}$.

SEM analysis showed that samples prepared without the addition of salt presented a dense morphology. Dense membranes based on
PCL possess irregular morphology on the casting surface characterized by agglomerates of the material suggesting a crystalline organization (Figure 2a). Analysis of the fracture surface (Figure 2b) confirms the concavities, however the material is internally dense and compact. Optical microscopy analyses were coupled with polarized light. Figure $2 \mathrm{c}$ shows the spherulites observed. The literature ${ }^{20}$ describes that casting process is sufficiently slow to allow the formation of spherulites domains similar to the ones observed in our experiment. Dense membranes based on PLGA50 are compact, plane and presents thickness regularity (Figure 2d). Changes were not observed in the morphology of the samples after 30 hours of immersion in distilled

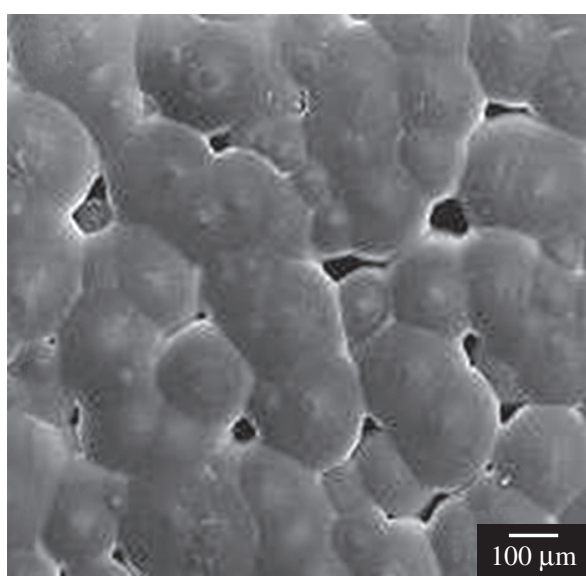

(a)

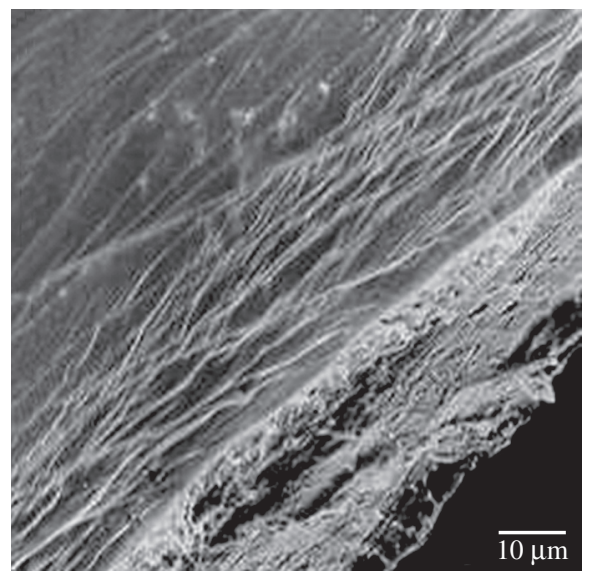

(d)

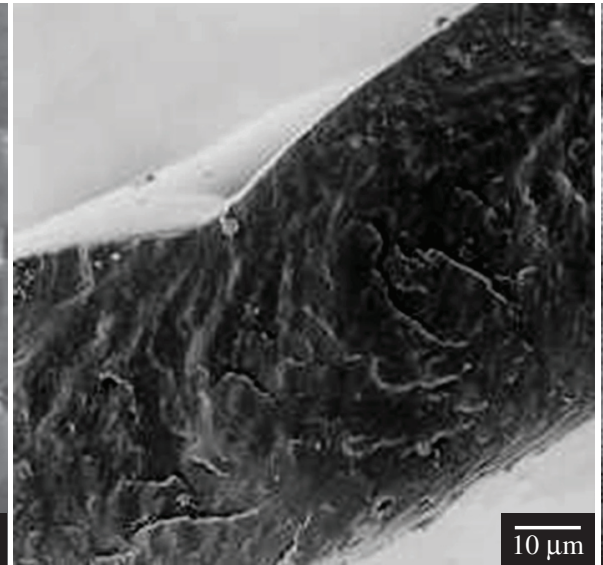

(b)

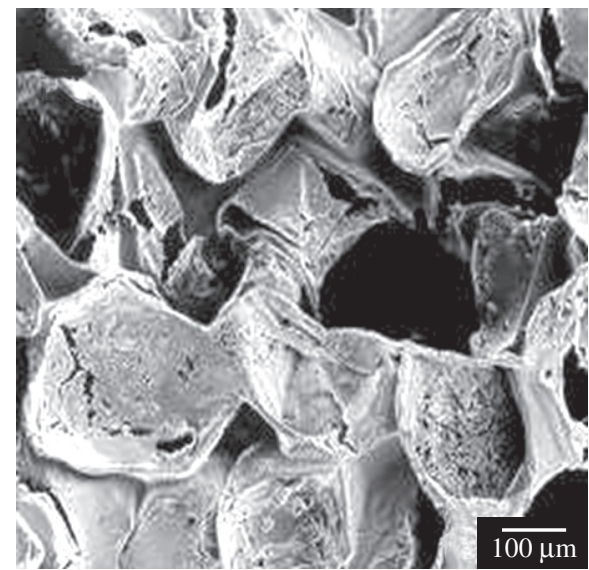

(e)

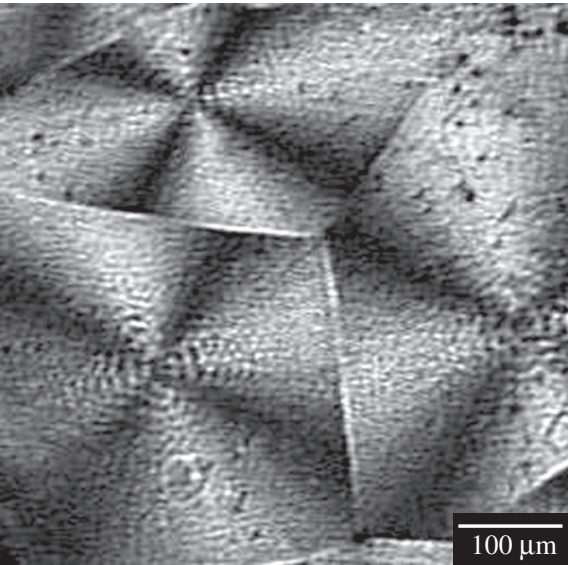

(c)

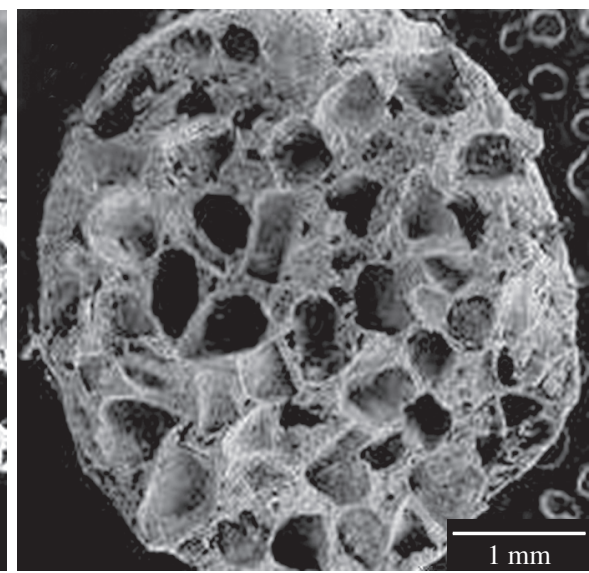

(f)

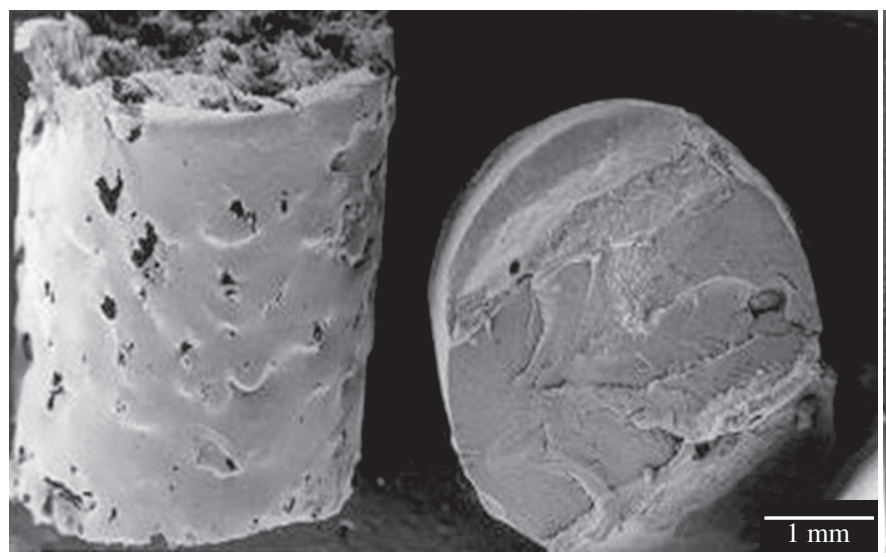

(g)

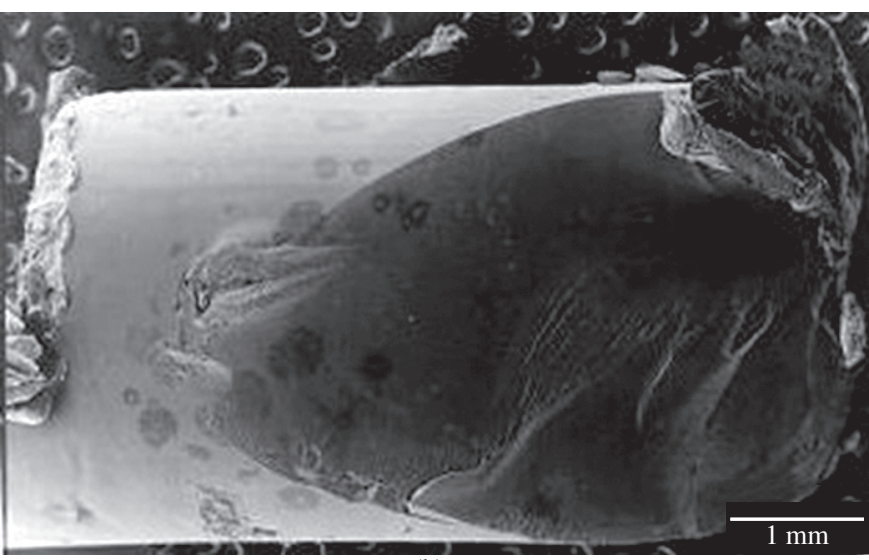

(h)

Figure 2. Scanning electron micrographs of PCL and PLGA50 scaffolds. a) and b) dense PCL membranes; c) Optic microscopy of PCL membranes; d) PLGA50 dense membranes; e) PCL porous membrane; f) PLGA50 porous rods; g) PCL porous (left) and dense (right) rods and h) PLGA50 dense rods. 


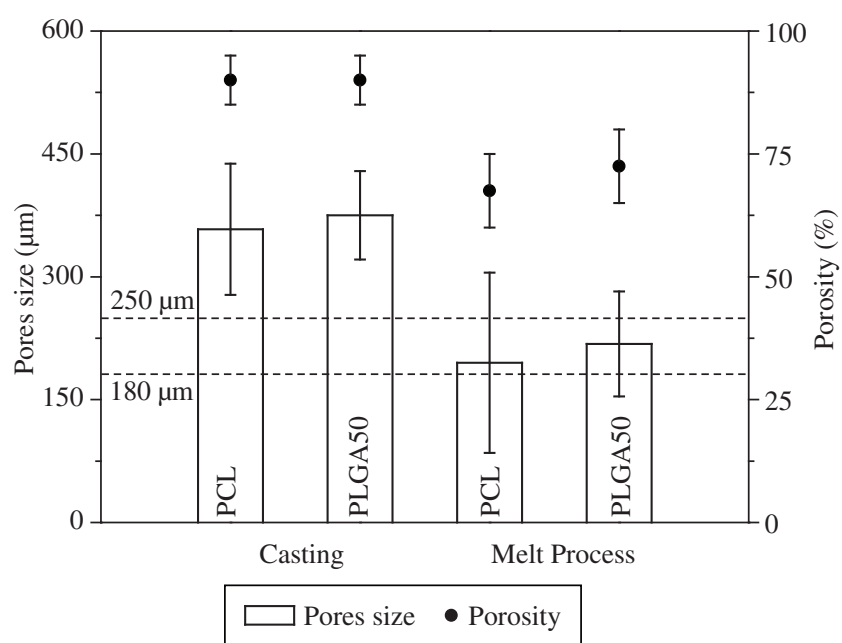

Figure 3. Average of pore sizes $(\mu \mathrm{m})$ and average porosity (\%) of PCL and PLGA50 scaffolds prepared by casting and melting compression process.
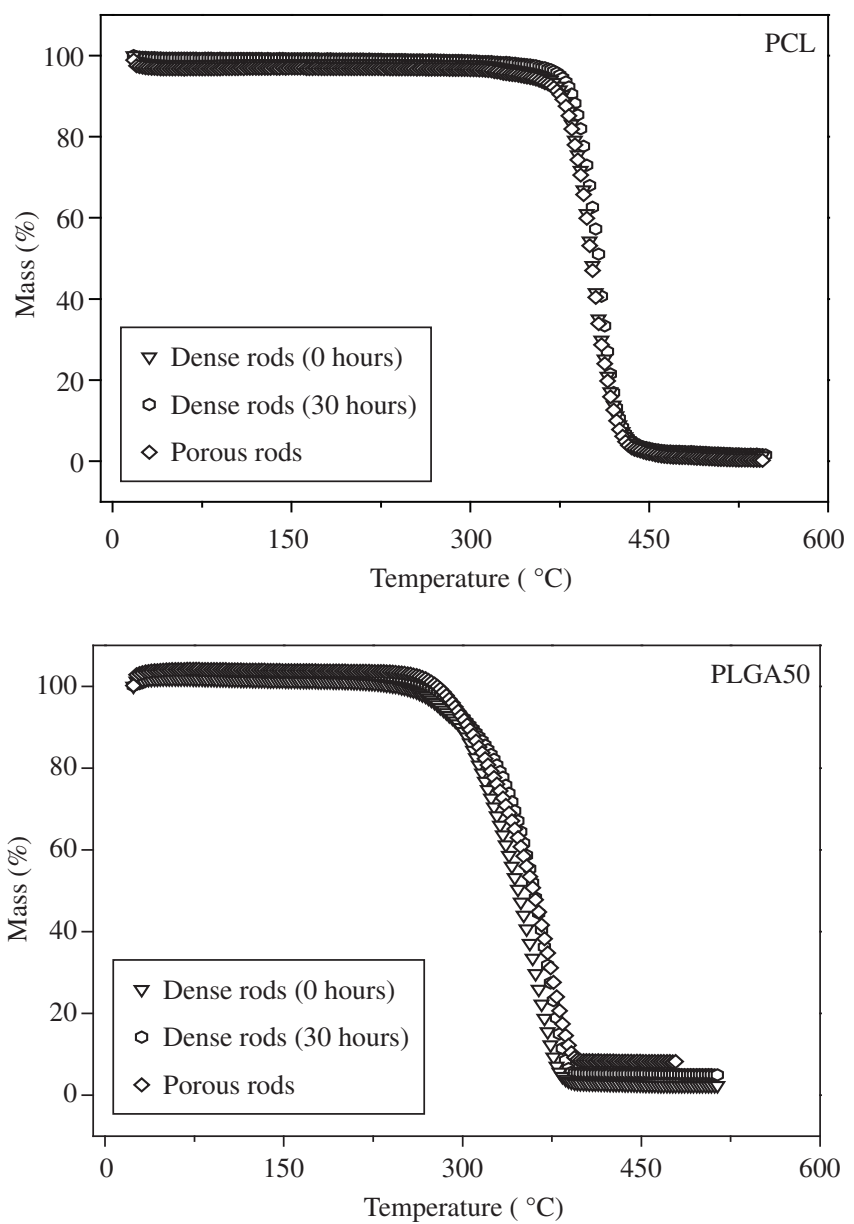

Figure 4. Thermogravimetric analysis of samples of PCL and PLGA50 prepared by melting compression process.

water (micrographs not shown). Membranes of PCL (Figure 2e) and PLGA50 prepared with salt addition and leaching process showed porous morphology. The samples showed an irregular surface with interconnected pores indicating the penetration of water and occur- rence of a dissociation process. Particles of salt were not observed in the analysis of the fracture surfaces. Morphologically, significant differences were not observed between the membranes prepared with PCL and PLGA50.

Dense rods (Figure $2 \mathrm{~g}$ and $2 \mathrm{~h}$ ) prepared by the melting compression process indicated similar morphologies. SEM analysis shows dense structure with flat surface due to the contact with the mold. Samples prepared with salt addition are porous and it was not possible to determine significant differences between the morphology of PCL and PLGA50 rods. Samples submitted to 30 hours of immersion did not present changes in their morphology.

Using the ImageTool ${ }^{\circledR}$ software, it was possible to estimate the porosity of the samples through the proportion of the areas of the pores, as shown in the Figure 3. Other methods for the determination of porosity have been proposed, such as the analysis using mercury porosimetry, however errors in the measurement of the flexibility of the samples are frequent ${ }^{21}$.

Porosity development depends on the processing technique and concentration of the salts. Scaffolds prepared by casting process allow the development of porosity higher than $87 \%^{10}$, which is similar to what was obtained in our experiment. Agrawal et al. ${ }^{22}$ established a proportional relationship between porosity and salt concentration: porosity increases approximately $5 \%$ within the salt concentration ranging from 80 to $90 \%$. The differences in the decrease in the size of the pores observed between the techniques could also be attributed to the processing conditions. During the fusion of the polymer, the saline portion is incorporated to the polymeric mass and the mixture is done manually in the melting process pot, this might have fragmented the particles.

In addition, an important parameter is the interconnection of the pores which is fundamental for tissue engineering applications. The interconnection allows an appropriate diffusion of the medium in the scaffold, facilitating the formation of tissues in an organized net Increases in salt concentrations allow a higher contact among the saline particles ${ }^{23}$.

In the field of tissue reconstructions, the pore sizes are related with the cell type. Determining the best size range of the pore represents one of the important focuses of researches in tissue engineering scaffolds $^{24}$. It has been reported fibroblast growth on scaffolds with pore sizes between 5 and $15 \mu \mathrm{m}^{25}$, hepatocytes on approximately $20 \mu \mathrm{m}^{26}$, skin regeneration between 20 and $150 \mu \mathrm{m}$ and neovascularization on $5 \mu \mathrm{m}^{27}$. In bone tissue engineering, the pore sizes vary between 100 and $400 \mu \mathrm{m}^{24}$.

DSC analyses of PCL samples are characteristic of a semi crystalline polymer while PLGA50 samples are typical of amorphous materials, identified by the presence of Tg and by the absence of Tm (Table 1). The degree of crystallinity of PCL samples was calculated from the melting enthalpy and showed that the samples of PCL varied between 40 and $60 \%$ without significant differences between dense and porous samples in the first heating and in the second heating. When comparing DSC values of samples that were not processed and dense samples (obtained by casting and melting process) no significant differences in the variables analyzed by the technique were observed.

The comparison of the morphology of the same material and different processes shows that there was no significant effect on the values of $\mathrm{Tg}$ and $\mathrm{Tm}$ in the absence of plasticizing agents such as water or solvent. Studies using PLGA scaffolds prepared by casting showed that leaching does not alter Tg, Tm or the degree of crystallinity of the material ${ }^{11,28}$.

The degree of crystallinity of PCL samples was shown to be grater in the casting process when compared to the melting compression technique. The differences can be attributed to the rate of solvent 
Table 1. Differential scanning calorimetric data for PCL and PLGA50 samples, without processing, before and after (30 hours) immersion in distilled water. $(\mathrm{Tg})$ glass transition, $(\mathrm{Tm})$ melting temperatures, $(\Delta \mathrm{Hm})$ melting enthalpies, $(\chi)$ degree of crystallinity.

\begin{tabular}{|c|c|c|c|c|c|c|}
\hline & & & $\operatorname{Tg}\left({ }^{\circ} \mathrm{C}\right)^{\mathrm{b}}$ & $\operatorname{Tm}\left({ }^{\circ} \mathrm{C}\right)^{\mathrm{a}}$ & $\Delta \mathrm{Hm}\left(\mathrm{J} \cdot \mathrm{g}^{-1}\right)^{\mathrm{a}}$ & $\chi(\%)^{\mathrm{a}}$ \\
\hline \multirow[t]{7}{*}{ PCL } & \multirow{3}{*}{ Casting } & Without processing & -64 & 65 & 80 & 58 \\
\hline & & Dense membrane (0 hours) & -66 & 65 & 85 & 61 \\
\hline & & Dense membrane (30 hours) & -65 & 64 & 86 & 62 \\
\hline & \multirow{4}{*}{$\begin{array}{l}\text { Melting } \\
\text { Compression }\end{array}$} & Porous membrane & -64 & 64 & 83 & 60 \\
\hline & & Dense rods (0 hours) & -64 & 62 & 72 & 49 \\
\hline & & Dense rods (30 hours) & -64 & 63 & 58 & 42 \\
\hline & & Porous rods & -63 & 63 & 63 & 45 \\
\hline \multirow[t]{7}{*}{ PLGA50 } & \multirow{3}{*}{ Casting } & Without processing & 39 & Amorphous & Amorphous & Amorphous \\
\hline & & Dense membrane (0 hours) & 40 & Amorphous & Amorphous & Amorphous \\
\hline & & Dense membrane (30 hours) & 39 & Amorphous & Amorphous & Amorphous \\
\hline & \multirow{4}{*}{$\begin{array}{l}\text { Melting } \\
\text { Compression }\end{array}$} & Porous membrane & 41 & Amorphous & Amorphous & Amorphous \\
\hline & & Dense rods (0 hours) & 44 & Amorphous & Amorphous & Amorphous \\
\hline & & Dense rods (30 hours) & 43 & Amorphous & Amorphous & Amorphous \\
\hline & & Porous rods & 44 & Amorphous & Amorphous & Amorphous \\
\hline
\end{tabular}

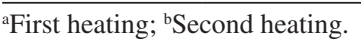

evaporation and cooling process. While the solvent evaporation occurs in approximately 24 hours, the cooling process is fast (approximately 5 minutes). Usually, slow processes allow the nucleation and formation of crystalline domains in the material, interfering in the quality and amount of the crystals ${ }^{29}$.

Using TGA analysis the samples were evaluated by initial temperature of mass loss (Tonset) prior to and after immersion in distilled water. The differences in the Tonset of the materials (PCL about $390^{\circ} \mathrm{C}$ and PLGA50 about $330{ }^{\circ} \mathrm{C}$ ) were attributed to their composition and crystallinity: the greater the content of linear carbon chains and the proximity to the polymeric chains, the greater the thermal stability of the material will be ${ }^{11}$. Figure 4 shows the agreement of the curves obtained for the dense and porous samples. The inclusion of citrate during the melting process didn't show differences in the analysis of TGA.

Thermal stability is an important factor in the manufacturing of bioresorbable scaffolds. In the studies of degradation and cell culture, the temperature is intentionally constant and maintained at approximately $37^{\circ} \mathrm{C}$. However, during heat processing of the material, thermal degradation can generate smaller molecules, as well as products and subproducts of degradation that can interfere with the chemical composition of the material and alter its cytotoxicity and biocompatibility ${ }^{30}$. The time of processing ( 2 to 3 minutes) in the heating pot during the melting process suggests that an analysis of the isotherm degradation kinetics would be useful to evaluate if the material suffers significant degradation. Nevertheless, the literature has not reported the degradation of polymers such as PCL and PLGA (50/50) at the processing temperature $\left(160^{\circ} \mathrm{C}\right)$ during short exposure periods ${ }^{31}$.

\section{Conclusions}

In this work two techniques were used to prepare dense and porous scaffolds of PCL and PLGA50. Samples prepared by casting process produce membranes whereas those submitted to melting compression produce rods. The leaching salt process used to obtain pores did not interfere in the properties of the material. The time of immersion of the samples in water for the removal of the salt is not long enough to alter the morphology and the thermal properties of the samples. The leaching salt process is reproductive and represents an alternative in the processing of bioresorbable scaffolds for cell culture in the field of tissue engineering.

\section{Acknowledgments}

This work was supported by The National Council for Scientific and Technological Development (CNPq).

\section{References}

1. Kulkarni RK, Pani KC, Leuman C, Leonard F. Polylactic acid for surgical implants. Archives of Surgery. 1966; 93: 839-843.

2. Avgoustakis K. Pegylated poly(lactide) and poly(lactide-co-glycolide) nanoparticles: preparation, properties and possible applications in drug delivery. Current Drug Delivery. 2004; 1(4): 321-333.

3. Waksman R. Biodegradable stents: they do their job and disappear. Journal of Invasive Cardiology. 2006; 18(2): 70-74.

4. Temenoff JS, Mikos AG. Review: tissue engineering for regeneration of articular cartilage. Biomaterials. 2000; 21: 431-440.

5. Griffith LG, Naughton G. Tissue Engineering-Current Challenges and Expanding Opportunities. Science. 2002; 295(8): 1009-1014.

6. Vert M, Li S, Garreau H. New insights on the degradation of bioresorbable polymeric devices based on lactic and glycolic acids. Clinical Materials. 1992; 10: 3-8.

7. Middleton JC, Tipton AJ. Synthetic biodegradable polymers as orthopedic devices. Biomaterials. 2000; 21: 2335-2346.

8. Ferreira BMP, Zavaglia CAC, Duek EAR. Films of PLLA/PHBV: Thermal, morphological, and mechanical characterizatio. Journal of Applied Polymer Science. 2002; 86: 2898-2906.

9. Barbanti SH, Zavaglia CAC, Duek EAR. Porous and dense poly(L-lactic acid) membranes: in vitro degradation. Acta Microscopica. 2002; 11(1): 85-89.

10. Mikos AG, Temenoff JS. Formation of highly porous biodegradable scaffolds for tissue engineering. Journal of Biotechnology. 2000; 3(2): 114-119.

11. Barbanti SH, Santos Jr, AR, Zavaglia, CAC, Duek, EAR, Porous and dense poly(L-lactic acid) and poly(D,L-lactic acid-co-glycolic acid) scaffolds: in vitro degradation in culture medium and osteoblasts culture. Journal of Materials Science: Materials in Medicine. 2004; 15: 1315-1321.

12. Eldsäter C, Erlandsson B, Renstad R, Albertsson A-C, Karlsson S. The biodegradation of amorphous and crystalline regions in film-blown poly(E-caprolactone). Polymer. 2000; 41: 1297-1304.

13. Lam KH, Nieuwenhuis P, Esselbrugge H, Feijen J, Dijkstra PJ, Schakeraad JM. Biodegradation of porous versus non porous poly(L-lactic 
acid) films. Journal of Materials Science: Materials in Medicine. 1994; 5: 181-193.

14. Mikos AG, Sarakinos G, Leite SM, Vacanti JP, Langer R. Laminated three-dimensional biodegradable foams for use in tissue engineering. 4 . 1993; 14(5): 323-330.

15. Hou Q, Grijpma DW, Feijen J. Porous polymeric structures for tissue engineering prepared by coagulation, compression moulding and salt leaching technique. Biomaterials. 2003; 24: 1937-1947.

16. Li S. Hydrolytic degradation characteristics of aliphatic polyesters derived from lactic and glycolic acids. Journal of Biomedical Materials Research. 1999; 48(3): 342-353.

17. Sung H-J, Meredith C, Johnson C, Galis ZS. The effect of scaffold degradation rate on three-dimensional cell growth and angiogenesis. Biomaterials. 2004; 25: 5735-5742.

18. Agrawal CM, Athanasiou KA. Technique to control $\mathrm{pH}$ in vicinity of biodegrading PLA-PLGA implants. Journal of Biomedical Materials Research (Applied Biomaterials). 1997; 38: 105-114.

19. Barbanti SH, Zavaglia CAC, Duek EAR. Degradação acelerada de suportes de poli(e-caprolactona) e poli(D,L-ácido láctico-co-ácido glicólico) em meio alcalino. Polímeros. 2006; 16(2): 141-148.

20. Tsuji H, Ikada Y. Proprierties and morphology of poly(L-lactide) 4. Effects os structural parameters on long-term hydrolysis of poly(L-lactide) in phosphate-buffered solution. Polymer Degradation and Stability. 2000; 67: 179-89.

21. Hedberg EL, Shih CK, Lemoine JJ, Timmer MD, Liebschner MA, Jansen JA, Mikos AG. In vitro degradation of porous poly(propylene fumarate)/ poly(DL-lactic-co-glycolic acid) composite scaffolds. Biomaterials. 2005; 26: 3215-3225.
22. Agrawal CM, McKinney JS, Lanctot D, Athanasiou K. Effects of fluid flow on the in vitro degradation kinetics of biodegradable scaffolds for tissue engineering. Biomaterials. 2000; 21: 2443-2453.

23. Guan J, Fujimoto KL, Sacks MS, Wagner WR. Preparation and characterization of highly porous, biodegradable polyurethane scaffolds for soft tissue applications. Biomaterials. 2005; 26: 3961-3971.

24. Sarazin P, Roy X, Favis BD. Controlled preparation and properties of porous poly(L-lactide) obtained from a co-continous blend of two biodegradable polymers. Biomaterials. 2004; 25: 5965-5978.

25. Wang M, Chen LJ, Weng J, Yue CY. Manufacture and evaluation of bioactive and biodegradable materials and scaffolds for tissue engineering. Journal of Materials Science: Materials in Medicine. 2001; 12: 855-860.

26. Maquet, V, Jerome, R, Design of macroporous biodegradable polymer scaffolds for cell transplantation in Porous Materials for Tissue Engineering. Materials Science Forum. 1997; 250: 15-42.

27. Atala A. Tissue engineering and regenerative medicine: concepts for clinical application. Rejuvenation Research. 2004; 7: 15-31.

28. Lu L, Peter SJ, Lymen MD, Lai H, Leite SM, Tamada JA, Vacanti JP, Langer R, Mikos AG. In vitro and in vivo degradation of porous poly(D,Llactic-co-glycolic acid) foams. Biomaterials. 2000; 21: 1837-1845.

29. Tang ZG, Black RA, Curran JM, Hunt JA, Rhodes NP, Williams DF, Surface properties and biocompatibility of solvent-cast poly[E-caprolactone] films Biomaterials, 2004; 25: 4741-4748.

30. Tiaw KS, Teoh SH, Chen R, Hong MH. Processing Methods of Ultrathin Poly( $\varepsilon$-caprolactone) Films for Tissue Engineering Applications. Biomacromolecules. 2007; 8(3): 807-816.

31. Aoyagi Y, Yamashita K, Doi Y. Thermal degradation of poly[(R)-3hydroxybutyrate], poly[E-caprolactone] and poly[(S)-lactide]. Polymer Degradation and Stability. 2002; 76: 52-59. 